\title{
Clinical Manifestations of Laryngopharyngeal Reflux
}

\author{
Sung Yong Han and Gwang Ha Kim* \\ Department of Internal Medicine, Pusan National University School of Medicine, and Biomedical Research Institute, Pusan National University \\ Hospital, Busan, Korea
}

Article: Laryngopharyngeal reflux in children with chronic otitis media with effusion

Górecka-Tuteja A, Jastrzębska I, Składzień J, Fyderek K

(J Neurogastroenterol Motil 2016;22:452-458)

Gastroesophageal reflux disease (GERD) is one of the most common diseases in Asia, affecting about 4.3-15.7\% of the adult population. ${ }^{1}$ GERD syndromes are classified as esophageal and extra-esophageal manifestations. ${ }^{2}$ Esophageal manifestations include heartburn, regurgitation and chest pain, while extra-esophageal manifestations include asthma, chronic cough, hoarseness, globus sensation, and laryngitis in adult patients. Laryngopharyngeal reflux (LPR) is considered the primary contributor to extra-esophageal symptoms. LPR is defined as the reflux of gastric content above the upper esophageal sphincter (UES). LPR symptoms appear in up to $60 \%$ of GERD patients. ${ }^{3,4}$ Most extra-esophageal syndromes in pediatrics are similar to those in adults; however, some syndromes, such as torticollis and serous otitis media (OM), are present mainly in pediatrics. ${ }^{5}$ However, the association between LPR and extraesophageal syndromes reported in adults has not yet been proven in pediatrics. Many previous studies have suggested an association between LPR and some extra-esophageal syndromes, including OM in pediatrics. ${ }^{6-9}$

In this issue of the Journal of Neurogastroenterology and Motility, Górecka-Tuteja et $\mathrm{al}^{10}$ described the correlation between LPR and OM in children, and defined LPR by using multichannel intraluminal impedance (MII) combined with dual-probe (pharyn- goesophageal) pH-metry (MII/pH). In children, OM is a common cause of acquired hearing loss, and its most important pathophysiology is impaired patency and dysfunction of the Eustachian tube. LPR is considered one of the risk factors of OM. In the study by Górecka-Tuteja et al, ${ }^{10} 19$ of 28 children (68\%) with OM had LPR, which is similar to the results found in previous studies (mean $49 \%$, range $27-71 \%$ ). ${ }^{8}$ Therefore, the authors suggest that LPR is an important risk factor of $\mathrm{OM}$ in children. In addition, the authors attempted to define LPR using $\mathrm{MII} / \mathrm{pH}$ in children. In adults, the superiority of $\mathrm{MII} / \mathrm{pH}$ compared with other modalities in the diagnosis of LPR has already been proven. ${ }^{11}$ Most previous studies in pediatrics used dual-probe $\mathrm{pH}$-metry to diagnose $\mathrm{LPR},{ }^{12,13}$ but LPR in pediatrics has not been defined by using this modality. The authors formulated the criteria to diagnose LPR using $\mathrm{MII} / \mathrm{pH}$ : (1) retrograde bolus movement in all 6 impedance channels and (2) a $\mathrm{pH}$ drop of at least 0.2 in the upper $\mathrm{pH}$ sensor upon the bolus reaching the pharynx.

According to American Gastroenterology Association Guidelines, ${ }^{2}$ LPR is not diagnosed solely based on laryngoscopic or endoscopic findings. A proton pump inhibitor (PPI) trial is recommended to treat the extra-esophageal syndromes in patients with typical GERD symptoms. On the other hand, a PPI trial is not

Received: June 13, 2016 Revised: None Accepted: June 13, 2016

() This is an Open Access article distributed under the terms of the Creative Commons Attribution Non-Commercial License (http://creativecommons. org/licenses/by-nc/4.0) which permits unrestricted non-commercial use, distribution, and reproduction in any medium, provided the original work is properly cited.

*Correspondence: Gwang Ha Kim, MD, PhD Department of Internal Medicine, Pusan National University School of Medicine, and Biomedical Research Institute, Pusan National University Hospital, 179 Gudeok-ro, Seo-gu, Busan 49241, Korea Tel: +82-51-240-7869, Fax: +82-51-244-8180, E-mail: doc0224@pusan.ac.kr 
recommended in patients with extra-esophageal syndromes who do not have typical GERD symptoms. The $\mathrm{pH}$ monitoring test is recommended for these patients. Because the association between LPR and OM in pediatrics is not clear, a PPI trial is generally not recommended for children with OM. ${ }^{5}$

As pepsin and pepsinogen are detected in the OM effusion with a high prevalence as a result of physiologic reflux, whether a causal relationship exists between pepsin/pepsinogen in the OM effusion and $\mathrm{OM}$ is unclear. ${ }^{6}$ Although it is important to investigate the association between LPR and OM, there is no consensus among guidelines pertaining to LPR diagnosis. ${ }^{2,14}$ Therefore, this study is meaningful in its attempt to define LPR using MII/pH. Further studies are needed to establish criteria more specific for LPR in children and to investigate their validity.

\section{Financial support: None.}

\section{Conflicts of interest: None.}

Author contributions: Sung Yong Han drafted and edited; and Gwang Ha Kim revised and performed the final approval of the manuscript.

\section{References}

1. Jung HK. Epidemiology of gastroesophageal reflux disease in Asia: a systematic review. J Neurogastroenterol Motil 2011;17:14-27.

2. Katz PO, Gerson LB, Vela MF. Guidelines for the diagnosis and management of gastroesophageal reflux disease. Am J Gastroenterol 2013;108:308-328.

3. Jaspersen D, Kulig M, Labenz J, et al. Prevalence of extra-oesophageal manifestations in gastro-oesophageal reflux disease: an analysis based on the ProGERD Study. Aliment Pharmacol Ther 2003;17:1515-1520.

4. Martinucci I, de Bortoli N, Savarino E, et al. Optimal treatment of laryngopharyngeal reflux disease. Ther Adv Chronic Dis 2013;4:287-301.

5. Sherman PM, Hassall E, Fagundes-Neto U, et al. A global, evidencebased consensus on the definition of gastroesophageal reflux disease in the pediatric population. Am J Gastroenterol 2009;104:1278-1295.

6. Tasker A, Dettmar PW, Panetti M, Koufman JA, Birchall JP, Pearson JP. Reflux of gastric juice and glue ear in children. Lancet 2002;359:493.

7. Crapko M, Kerschner JE, Syring M, Johnston N. Role of extra-esophageal reflux in chronic otitis media with effusion. Laryngoscope 2007;117: 1419-1423.

8. Miura MS, Mascaro M, Rosenfeld RM. Association between otitis media and gastroesophageal reflux: a systematic review. Otolaryngol Head Neck Surg 2012;146:345-352.

9. Havemann BD, Henderson CA, El-Serag HB. The association between gastro-oesophageal reflux disease and asthma: a systematic review. Gut 2007;56:1654-1664.

10. Górecka-Tuteja A, Jastrzębska I, Składzień J, Fyderek K. Laryngopharyngeal reflux in children with chronic otitis media with effusion. J Neurogastroenterol Motil 2016;22:452-458.

11. Lee BE, Kim GH, Ryu DY, et al. Combined dual channel impedance/ $\mathrm{pH}$-metry in patients with suspected laryngopharyngeal reflux. J Neurogastroenterol Motil 2010;16:157-165.

12. Chiou E, Rosen R, Nurko S. Effect of different $\mathrm{pH}$ criteria on dualsensor $\mathrm{pH}$ monitoring in the evaluation of supraesophageal gastric reflux in children. J Pediatr Gastroenterol Nutr 2011;52:399-403.

13. Keleş B, Oztürk K, Günel E, Arbağ H, Ozer B. Pharyngeal reflux in children with chronic otitis media with effusion. Acta Otolaryngol 2004; 124:1178-1181.

14. Vakil N, van Zanten SV, Kahrilas P, Dent J, Jones R; Global Consensus G. The Montreal definition and classification of gastroesophageal reflux disease: a global evidence-based consensus. Am J Gastroenterol 2006;101:1900-1920. 